Forum

\title{
Stay or go - how topographic complexity influences alpine plant population and community responses to climate change
}

\author{
Bente J. Graae ${ }^{\mathrm{a}, *, 1}$, Vigdis Vandvik ${ }^{\mathrm{b}, 1}$, W. Scott Armbruster ${ }^{\mathrm{c}}$, Wolf L. Eiserhardt ${ }^{\mathrm{d}, \mathrm{e}}$, \\ Jens-Christian Svenning ${ }^{\mathrm{e}, \mathrm{q}}$, Kristoffer Hylander ${ }^{\mathrm{f}}$, Johan Ehrlén ${ }^{\mathrm{f}}$, James D.M Speed ${ }^{g}$, \\ Kari Klanderud $^{\mathrm{h}}$, Kari Anne Bråthen ${ }^{\mathrm{i}}$, Ann Milbau ${ }^{\mathrm{j}}$, Øystein H. Opedal ${ }^{\mathrm{k}}$, Inger G. Alsos ${ }^{1}$, \\ Rasmus Ejrnæs $^{\mathrm{m}}$, Hans Henrik Bruun ${ }^{\mathrm{n}}$, H. John B. Birks ${ }^{\mathrm{b}}$, Kristine B. Westergaard ${ }^{\circ}$,
} Hilary H. Birks ${ }^{\mathrm{b}}$, Jonathan Lenoir ${ }^{\mathrm{p}}$

a Department of Biology, Norwegian University of Science and Technology, Norway

b Department of Biology, University of Bergen, Norway

${ }^{\mathrm{c}}$ School of Biological Sciences, University of Portsmouth, United Kingdom, Institute of Arctic Biology, University of Alaska, USA

${ }^{\mathrm{d}}$ Comparative Plant and Fungal Biology Department, Royal Botanic Gardens, Kew, United Kingdom

${ }^{\mathrm{e}}$ Section for Ecoinformatics and Biodiversity, Department of Bioscience, Aarhus University, Ny Munkegade 114, DK-8000 Aarhus C, Denmark

${ }^{\mathrm{f}}$ Dept. of Ecology, Environment and Plant Sciences, Stockholm University, Sweden

${ }^{g}$ NTNU University Museum, Norwegian University of Science and Technology, Norway

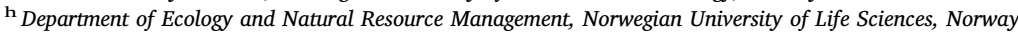

${ }^{i}$ Department of Arctic and Marine Biology, UiT - The Arctic University of Norway, Norway

${ }^{\mathbf{j}}$ Research Institute for Nature and Forest INBO, Department of Biodiversity and Natural Environment, Belgium

${ }^{\mathrm{k}}$ Centre for Biodiversity Dynamics, Department of Biology, Norwegian University of Science and Technology, Norway

${ }^{1}$ Tromsø Museum, University of Troms $\emptyset$ - The Arctic University of Norway, Norway

${ }^{\mathrm{m}}$ Section for Biodiversity and Conservation, Department of Bioscience, Aarhus University, Denmark

${ }^{\mathrm{n}}$ Department of Biology, University of Copenhagen, Denmark

${ }^{\circ}$ Norwegian Institute for Nature Research - NINA, Norway

P UR 'Ecologie et Dynamique des Systèmes Anthropisés' (EDYSAN, FRE 3498 CNRS-UPJV), Jules Verne University of Picardy, France

${ }^{\mathrm{q}}$ Center for Biodiversity Dynamics in a Changing World (BIOCHANGE), Aarhus University, Ny Munkegade 114, DK-8000 Aarhus C, Denmark

\section{A R T I C L E I N F O}

\section{Keywords:}

Adaptation

Dispersal

Microclimate

Niche

Refugia

Resilience

\begin{abstract}
A B S T R A C T
In the face of climate change, populations have two survival options - they can remain in situ and tolerate the new climatic conditions ("stay"), or they can move to track their climatic niches ("go"). For sessile and smallstature organisms like alpine plants, staying requires broad climatic tolerances, realized niche shifts due to changing biotic interactions, acclimation through plasticity, or rapid genetic adaptation. Going, in contrast, requires good dispersal and colonization capacities. Neither the magnitude of climate change experienced locally nor the capacities required for staying/going in response to climate change are constant across landscapes, and both aspects may be strongly affected by local microclimatic variation associated with topographic complexity. We combine ideas from population and community ecology to discuss the effects of topographic complexity in the landscape on the immediate "stay" or "go" opportunities of local populations and communities, and on the selective pressures that may have shaped the stay or go capacities of the species occupying contrasting landscapes. We demonstrate, using example landscapes of different topographical complexity, how species' thermal niches could be distributed across these landscapes, and how these, in turn, may affect many population and community ecological processes that are related to adaptation or dispersal. Focusing on treeless alpine or Arctic landscapes, where temperature is expected to be a strong determinant, our theorethical framework leads to the hypothesis that populations and communities of topographically complex (rough and patchy) landscapes should
\end{abstract}

\footnotetext{
This article is part of a special issue entitled Alpine and arctic plant communities: a worldwide perspective published at the journal Perspectives in Plant Ecology, Evolution and Systematics 30C.

* Corresponding author at: Department of Biology, Høgskoleringen 5, NO-7491 Trondheim, Norway.

${ }^{1}$ Graae and Vandvik contributed equally to the writing of the manuscript.

E-mail addresses: bente.j.graae@ntnu.no (B.J. Graae), Vigdis.Vandvik@uib.no (V. Vandvik), wsarmbruster@alaska.edu (W.S. Armbruster), W.Eiserhardt@kew.org (W.L. Eiserhardt), svenning@bios.au.dk (J.-C. Svenning), kristoffer.hylander@su.se (K. Hylander), Johan.Ehrlen@su.se (J. Ehrlén), James.Speed@ntnu.no (J.D.M. Speed), kari.klanderud@nmbu.no (K. Klanderud), kari.brathen@uit.no (K.A. Bråthen), ann.milbau@inbo.be (A. Milbau), oystein.h.opedal@ntnu.no (Ø.H. Opedal), inger.g.alsos@uit.no (I.G. Alsos), rasmus@bios.au.dk (R. Ejrnæs), hhbruun@bio.ku.dk (H.H. Bruun), John.Birks@uib.no (H.J.B. Birks), Kristine.Westergaard@nina.no (K.B. Westergaard), Hilary.Birks@uib.no (H.H. Birks), jonathan.lenoir@u-picardie.fr (J. Lenoir).
} 
be both more resistant and more resilient to climate change than those of topographically simple (flat and homogeneous) landscapes. Our theorethical framework further points to how meta-community dynamics such as mass effects in topographically complex landscapes and extinction lags in simple landscapes, may mask and delay the long-term outcomes of these landscape differences under rapidly changing climates.

\section{Introduction}

Our understanding of the magnitude and ecological implications of climatic variation in space and time has greatly developed over the past decades. Studies focusing on the capacity for species to track their climatic niches over large spatial extents, including palaeoecological reconstructions (reviewed in Feurdean et al., 2013) and climate envelope models (Pearson and Dawson, 2003; Sykes et al., 1996), typically suggest high migration rates in response to rapid redistribution of climates at the global scale (Clark et al., 1998; Loarie et al., 2009). For plants, these findings have been challenged by more recent molecular (Westergaard et al., 2010, 2011), palaeoecological (Birks and Willis, 2008; Cheddadi et al., 2014) and mesoto micro-scale climate envelope modelling (Franklin et al., 2013; Lenoir et al., 2017; Randin et al., 2009; Trivedi et al., 2008), all suggesting occasional species persistance within refugia or through short-distance escapes (Hampe and Jump 2011). Here, we discuss how the propensity for species to "stay", through adaptation processes, or "go", through dispersal processes, so as to survive in the face of climate change, depends not only on the magnitude of climate-change exposure and the climate-change sensitivity of the constituent species and communities (Dickinson et al., 2014; Bertrand et al., 2016), but also on the spatial structure of the landscapes in which the species occur (Körner, 2004; Slavich et al., 2014).

Topography is a key determinant of climatic variation across spatial scales ranging from regions, covering hundreds of square kilometres, to microsites of less than a square metre, especially in treeless areas like the high Arctic and alpine regions (see Box 1). Across these spatial scales, we can find regions, landscapes, patches, and microsites that are relatively topographically uniform, as well as others that are topographically complex, with associated differences in climatic heterogeneity. For example, there are clear differences in topographic complexity between mountainous $v$ s. flat landscapes in high-latitude regions (Lenoir et al., 2013), flat areas $v s$. ridge-snowbed gradients in alpine landscapes (Graae et al., 2011; Körner, 2003), and flat vs. microtopographically complex patches within grassland and tundra vegetation (Armbruster et al., 2007; Moeslund et al., 2013; Opedal et al., 2015). The topographic complexity at scales of a few tens of metres can give rise to microclimatic variation in e.g., mean temperatures that often matches what is expected under future climate change scenarios $\left(2-6^{\circ} \mathrm{C}\right.$; Armbruster et al., 2007; Dobrowski et al., 2013; Graae et al., 2012; Lenoir et al., 2013; Opedal et al., 2015; Scherrer and Körner, 2010; Scherrer and Körner, 2011).

It is important to focus on high-latitude and high-elevation landscapes beyond treeline, not only because the complex topography there provides more spatial heterogeneity in temperature, but especially because temperature itself is expected to be the main determinant of plant distribution in these landscapes (Körner, 2003; Raunkiaer 1934). Indeed, temperature has both direct effects on alpine plant life through setting limits to species' fundamental niches, as well as indirect effects through determining, for instance, decomposition and nutrient cycling, access to water, as well as the abundance of herbivores, pathogens, pollinators, and seed dispersers. Some of these variables are also influenced by other factors - for instance anthropogenic disturbances and herbivore density that are often also regulated by humans. As Box 1 illustrates, we need to incorporate all these various components of temperature into the thermal niche concept of alpine plants. Hence, the thermal niche of an alpine plant species becomes a somewhat theoretical object for which one has to make the often unrealistic assumption of ceteris paribus ("other things being equal"). Though the realized niche for a species is difficult to describe because of the complexity of interacting limiting factors, there are good evidence for the existence of microclimatic niches (Lenoir et al., 2013; Scherrer and Körner 2011). In this paper we will make use of this theoretical niche concept, arguing that realised microclimatic niches are important for plants and improving our understanding of the distribution of these thermal niches across the landscape is important for predicting species' capacities to adapt or disperse in response to changing climate.

Here, we synthesise theories relevant for how the topographic complexity of landscapes at high elevations or latitudes influences the

Box 1

The thermal niche of alpine plants.

The thermal niche of plants is often described in a highly simplified manner with a strong focus on synoptic or ambient air temperature characterizing macroclimate. For small-stature and slow-growing alpine and Arctic plants there is a major difference and decoupling between the temperature that the plants experience near the ground and the temperature conditions obtained from weather stations measuring synoptic temperature at $2 \mathrm{~m}$ height (Graae et al., 2012; Lenoir et al., 2013; Körner, 2003; Scherrer and Körner, 2010, 2011). During summer, the difference and decoupling between temperature conditions near the ground and synoptic temperature is to a high degree controlled by topography, vegetation structure, proximity to ground and, in the soil, also the moisture level. During winter, difference and decoupling is also caused by topography, vegetation structure and proximity to ground, but this is mostly due to its effect on snow cover and depth that determines the microclimate (temperature and moisture) and light conditions to the plants. Körner (2003) as well as Wipf and Rixen (2010) describes in detail how snow cover and duration matters for alpine and Arctic vegetation.

In addition to these scale effects, it is well established that the multifaceted nature of temperature (maximum, minimum, mean, growing season length, etc.) affects different life cycle and phenological stages to various extent. For instance, extreme temperatures are mostly associated with mortality events and the timing of these extreme events is crucial, whereas mean temperatures are chiefly associated with growth processes. Körner et al. (2016) describe how the many different components of climate affect tree distribution, and this complexity of niche limiting factors and interactions is expected to be even greater for small-stature plants occurring near the ground. Understanding the ecophysiological and ecological mechanisms underlying plant species distribution needs to take such microclimatic considerations into account. Accounting for all these limiting factors to model alpine plant species distribution is rarely done in the scientific literature. The more simplified concept of thermal niche has, however, shown useful because plant species distribution, especially trees for which most studies are done, correlate well with macroclimatic variables such as mean summer and winter temperatures. However, for mechanistic understanding of what is driving these correlations we need to go beyond mean temperatures (Körner et al., 2016) and assess the importance of this topographically-driven heterogeneity in temperature conditions near the ground and its consequences for alpine plant distribution and redistribution under climate change. 


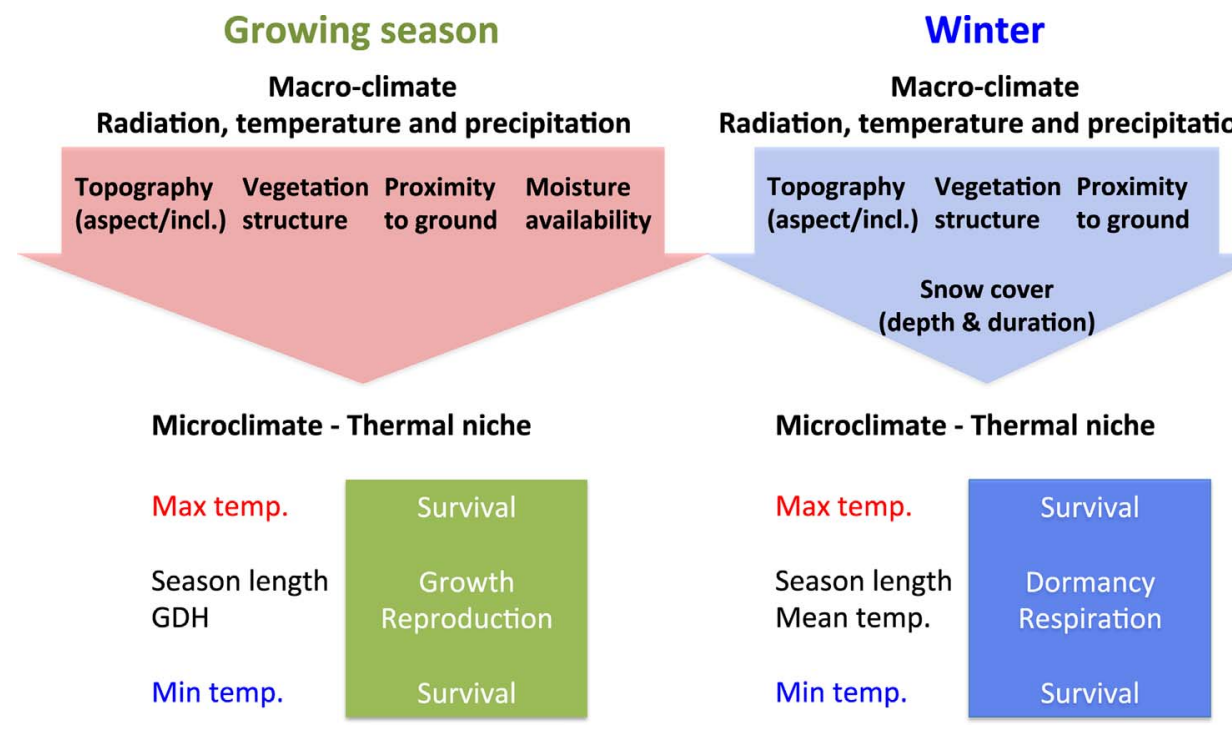

Legend: Diagram showing the many factors shaping the microclimatic niche in alpine plant communities. The growing season macroclimate is filtered into microclimate by factors listed in the red arrow and winter macroclimate is filtered into microclimate by factors listed in the blue arrow. The resulting summer microclimatic niche in green for survival, growth and reproduction of plants are determined by temperature extremes (max. and min. temperatures mostly for survival), season length and growing degree hours (GDH) that gives the accumulated temperature for growth and reproduction. Also the winter microclimatic niche in blue is determined by the temperature extremes for survival while season length, that also to a high extent is driven by snow cover, determines important winter processes, for instance respiration and dormancy break.

resistance (the lack of sensitivity and response to perturbation or disturbance) and resilience (the capacity to recover after perturbation or disturbance) of alpine plant populations and communities in response to climate change. Specifically, we explore (1) how populations in landscapes of different topographical complexity are affected by microclimatic heterogeneity under the current climate, and (2) how this may affect their responses to climate change. We then turn to communities, and (3) develop a framework for community response to landscape microclimatic heterogeneity, before we (4) ask how this may affect community-level responses to climate change in landscapes of different topographic complexity. Although we focus on small-stature plants in cold ecosystems, many of the processes we describe here would hold for other groups of organisms, with modifications to account for differences in organism mobility and scale (Roth et al., 2014), as well as other important factors of specific relevance. For example, for small-stature plants in the lowlands, one would also have to consider, in addition to topography, the effect that tree or shrub canopy cover exerts on microclimate (De Frenne et al., 2013; Grimmond et al., 2000) and its consequences for forest plant species distribution (e.g. Wesser and Armbruster 1991; Lenoir et al., 2017).

\section{The spatial components of microclimatic niche heterogeneity}

Microclimatic heterogeneity affects populations and communities in two general ways. First, by increasing the range of climatic conditions, it increases the climatic niche space that is available within a given surface area and creates potential niche space for more species. At the same time, this inevitably comes at the expense of reduced available habitat area (Kerr and Packer, 1997; Scherrer and Körner, 2011) and thus increases habitat fragmentation (Reino et al., 2013) for species with specialised thermal niches. In alpine and Arctic ecosystems, topography is the main physiographic feature that can enhance microclimatic heterogeneity in space. As a general and simplified example, consider seven hypothetical landscapes of equal size (e.g., $1 \mathrm{~km}^{2}$ ), sharing a regional plant species pool (Zobel, 1997), but varying in topographic complexity (Fig. 1). Microclimatic heterogeneity due to topographic complexity has two dimensions: the range of climatic conditions available (increasing from left to right in Fig. 1), and the climatic patchiness or fragmentation (increasing from top to bottom in Fig. 1). The species in the regional pool will be distributed differently among and within the landscapes, depending on niche availability and landscape heterogeneity (in Fig. 1, species are represented by rings and curves of different colours). In addition to experiencing long-term changes in climatic conditions, our hypothetical landscapes can experience different levels of disturbance and seasonal fluctuation, which will naturally influence the population and community dynamics of the plants inhabiting these landscapes. Additionally, alpine plant species have different life histories, sizes and dispersal capacities, involving different spatial scales (cf. the spatial extent and resolution of our hypothetical landscapes). Here, we only focus on the spatial arrangement of microclimatic conditions across a 1-km landscape and the impact of climate change on the "stay" or "go" processes.

Our first example landscape, L0, is climatically homogeneous, with a narrow range of climatic conditions (or niche space), such as can be found for temperature across a flat and smooth landscape. For species whose realised climatic niche requirements are fulfilled in this landscape (species represented by the brown and green curves and rings in Fig. 1), a large and continuous habitat area is available, and the probability of temperaturerelated local extinction under stable conditions is hence low (Hanski, 1998; Lande, 1993; MacArthur and Wilson, 1963). L1 and L2 encompass increasingly wider ranges of thermal conditions that are distributed in a non-patchy way (positive spatial autocorrelation) such as on a gentle (L1) or a steep (L2) hillside. The available niche space, and hence the potential number of species in the landscape increases from L0 via L1 to L2 (Fig. 1). Depending on the species' niche width and the climatic niche availability, species may occur in the whole or in parts of the landscape, and there is, for most species, less habitable area available in L2 than in L1 and L0.

L3 has the same available thermal niche space for any given species as L1, but suitable areas for each species are more patchily distributed in space, and the populations will therefore tend to be more spatially scattered, as in a hilly landscape with fine-scale topographic complexity. Landscapes L2 and L4 have the same difference in patchiness as between L1 and L3 but with a larger climatic range. Thus, L3 and L4 have, on 


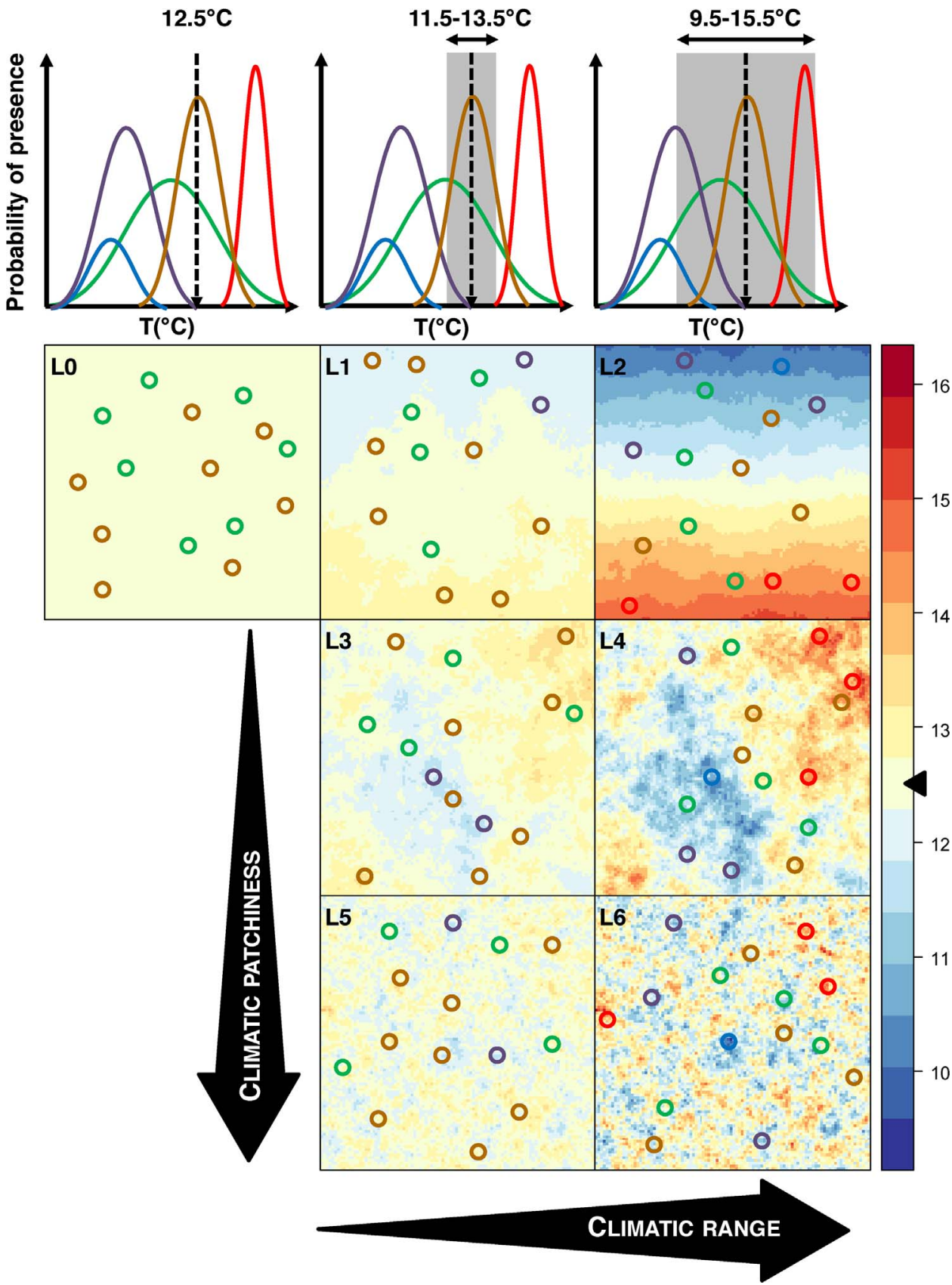

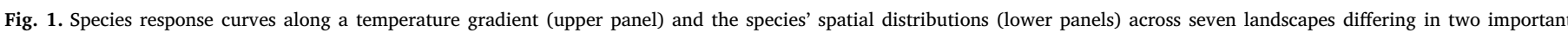

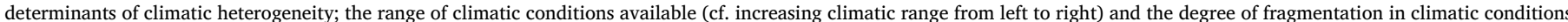

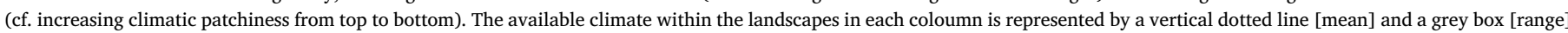

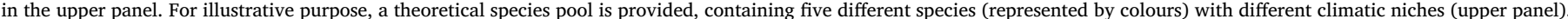

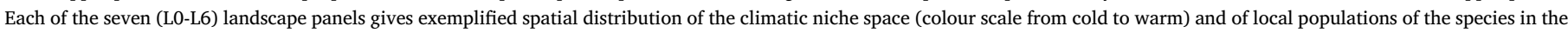
species pool (coloured rings). Note that the mean temperature is similar across all seven landscapes - illustrated by the black triangle on the key to the right.

average, smaller patches, but also shorter distances between patches of suitable habitat, compared to landscapes L1 and L2, respectively. Landscapes L5 and L6 are even more fragmented, to the extent that they may appear quasi-homogeneous.

Below, we evaluate how the increasing landscape heterogeneity affects the populations and communities inhabiting these different landscapes. We outline the consequences of this landscape heterogeneity for the selective pressures within the different landscapes, and for how the populations and communities are equipped to respond to climate change.

\section{Populations in landscapes of varying climatic heterogeneity}

For species with narrow thermal niches and/or only occurring in part of the climatic range of the landscape (i.e. purple species in L1, L3 and L5 and blue species in L2, L4 and L6), populations will be smaller in size and/or more fragmented in space going from L0 towards L6. This may lead to higher local extinction rates due to stochastic processes in the smaller populations of fragmented landscapes (Fig. 1). However, when moving from L3 to L5 or from L4 to L6 the existence of many small patches will reduce the average distance between patches of suitable habitat in these landscapes, potentially improving connectivity between the fragmented populations and reducing extinction risks via rescue effects (Brown and KodricBrown, 1977; Hanski, 1998). Note that this potential increase in connectivity can only happen if the average dispersal distance of the focal plant species within the landscape exceeds the average distance between patches of suitable habitat (i.e., the patches are part of a population or meta- 
population, sensu Hanski, 1998). In our example with a fixed sized landscape window, the balance between extinctions, caused by reduced patch sizes, and colonisations, caused by reduced distances between the patches and by the area-related colonization capacity, will depend on the organisms' life history. Small sized and well-dispersed plant species will most likely be less affected by decreasing habitat sizes and increasing isolation than plant species with high area requirement or more limited colonisation capacities.

Interestingly, the population processes in climatically variable and patchy landscapes, like L6, may converge towards the situation in homogeneous landscapes such as L0 if distances are so small that individuals can easily move between patches so that populations are no longer fragmented. However, in contrast to L0, highly heterogeneous landscapes as in L6 may allow populations with different niche requirements to coexist, as long as the patch area across the landscape is still large enough for populations to survive locally. Therefore, the constraint due to dispersal limitation towards a climatically suitable location may become less important towards both L6 (i.e. similar microclimates can be very close) and L0 (i.e. homogeneous microclimatic conditions), and may be most important under intermediate microclimatic heterogeneity (relative to the organism under study).

The microclimatic heterogeneity in the landscape will also alter the selective forces acting on populations in the different landscape types. Populations inhabiting climatically heterogeneous landscapes may be under selection for broader niches in order to maintain sustainable population sizes in a heterogeneous environment. When microclimatic heterogeneity increases, either moving from left to right or top to bottom in Fig. 1, species with broad climatic niches, represented by the green curve, will have an advantage compared to the species with narrower niches. Selection for broader niches may result in greater phenotypic plasticity within local populations, with important consequences for the capacity of these populations to respond to environmental changes (Chevin et al., 2010; Jump and Peñuelas, 2005; Nicotra et al., 2010). Whether selection in response to environmental heterogeneity favours phenotypic plasticity, genetic differentiation, or a combination of the two, depends on several factors, including the temporal and spatial scale of climatic variation (Alpert and Simms, 2002; Botero et al., 2015). More effective dispersal in space or time may also counteract the negative effects of fragmentation. Populations in fragmented landscapes may therefore also be under selection towards better dispersal abilities, or they may be under selection towards better survival in dormant or other long-lived stages, thus contributing to extinction time-lags, until opportunities for continued growth and reproduction (re)appear locally (dispersal in time or remnant population strategy sensu Eriksson, 1996).

\section{Consequences of microclimatic heterogeneity for populations under changing climate}

Populations in different landscape types, such as topographically simple $v s$. complex terrains, may be very differently positioned, and also equipped, to meet ecological challenges of climate change. In a climatically homogeneous landscape, like L0, populations can remain within the landscape if they tolerate the new climatic conditions, either through intrinsic ability of individuals to tolerate changing climatic conditions (Bertrand et al., 2016), or through intraspecific variation in the position of the climatic niche optima (Valladares et al., 2014). Alpine plant species within the homogeneous landscapes are expected to have rather narrow niches, but those with the widest climatic niches, represented by the green curve in Fig. 1, will have the highest chance of surviving in this type of landscape and adapting to the new climatic conditions through realised niche shifts (Wasof et al., 2013, 2015). Indeed, in L0, distances to new suitable habitats might be relatively large (i.e., somewhere outside the landscape), thus favouring adaptation ("stay") processes over dispersal and colonisation ("go") processes. In addition, low immigration rates into patches in these landscapes (i.e., long distance to source populations of species with different climatic optima) means that the resident species will have a relatively low risk of being exposed to competition from immigrant species better adapted to the new climate (Ackerly, 2003; Bertrand et al., 2011). This may allow persistence under a new suboptimal climate and hence a longer time during which adaptation to the new climate can occur (Ackerly, 2003; Svenning and Sandel, 2013). Species with high persistence capacity, for instance with very long-lived individuals or dormant stages, may remain for extended periods in this type of landscape (L0) compared to what would be predicted from their climatic niche (Eriksson, 1996, 2000; May et al., 2009; Migliore et al., 2013), contributing to the extinction debt (Tilman, 1994). Related to this, "staying" may also be possible through expansion of the realised niche to encompass the new climate, for example due to changes in biotic interactions (e.g. competitive release (Lenoir et al., 2010)).

In contrast, populations experiencing changing climate in more heterogeneous landscapes (to the right or down in Fig. 1) are more likely to

Box 2

The meta-community paradigm.

The meta-community paradigm defines a meta-community as a set of local communities, linked by dispersal, and describes how the dynamics of the meta-community at large is driven by the interactive effects of local niche processes operating within each patch, and by dispersal between patches (Leibold et al., 2004). Four general and non-mutually exclusive perspectives on meta-community dynamics are typically recognized:

- Neutral processes assume that all species within a trophic level and all patches are functionally equivalent and coexistence is permitted by stochastic processes and slow competitive exclusion relative to immigration and evolutionary rates (Hubbell, 2001).

- Patch dynamics models describe a system where coexistence is permitted by a trade-off between dispersal and competitive ability, so that the most successful colonizers of available patches are relatively poor competitors, and vice versa (Levins and Culver, 1971; Tilman, 1994).

- Species sorting models assume an environmentally heterogeneous environment and consider how species' niche requirements 'sort' them into local communities (Chase and Leibold, 2003; Whittaker, 1962).

- Mass effects models build on species sorting, but with the added feature that dispersal between communities may allow maintenance of local 'sink' populations also in sites where the niche requirements of that species are not met (Holt, 1993; Mouquet and Loreau, 2003).

In the past decade, the meta-community paradigm has been highly influential in setting the research agenda in community ecology, and it has inspired a substantial literature on the interplay between dispersal and niche processes, covering a wide range of spatial and temporal scales, biomes, and organism groups, and giving rise to both theoretical, observational and experimental advances (Leibold et al., 2010; Murphy and Foster, 2014; Myers and Harms, 2009; Pillar and Duarte, 2010; Telford et al., 2006; Tscharntke et al., 2012; Urban et al., 2008). However, questions of the relative importance of the different meta-community processes in determining the patterns in community composition we observe in nature, and indeed how and if the relative importance of these processes can even be quantitatively assessed, have been highly debated and are far from being resolved (e.g., Logue et al., 2011). 


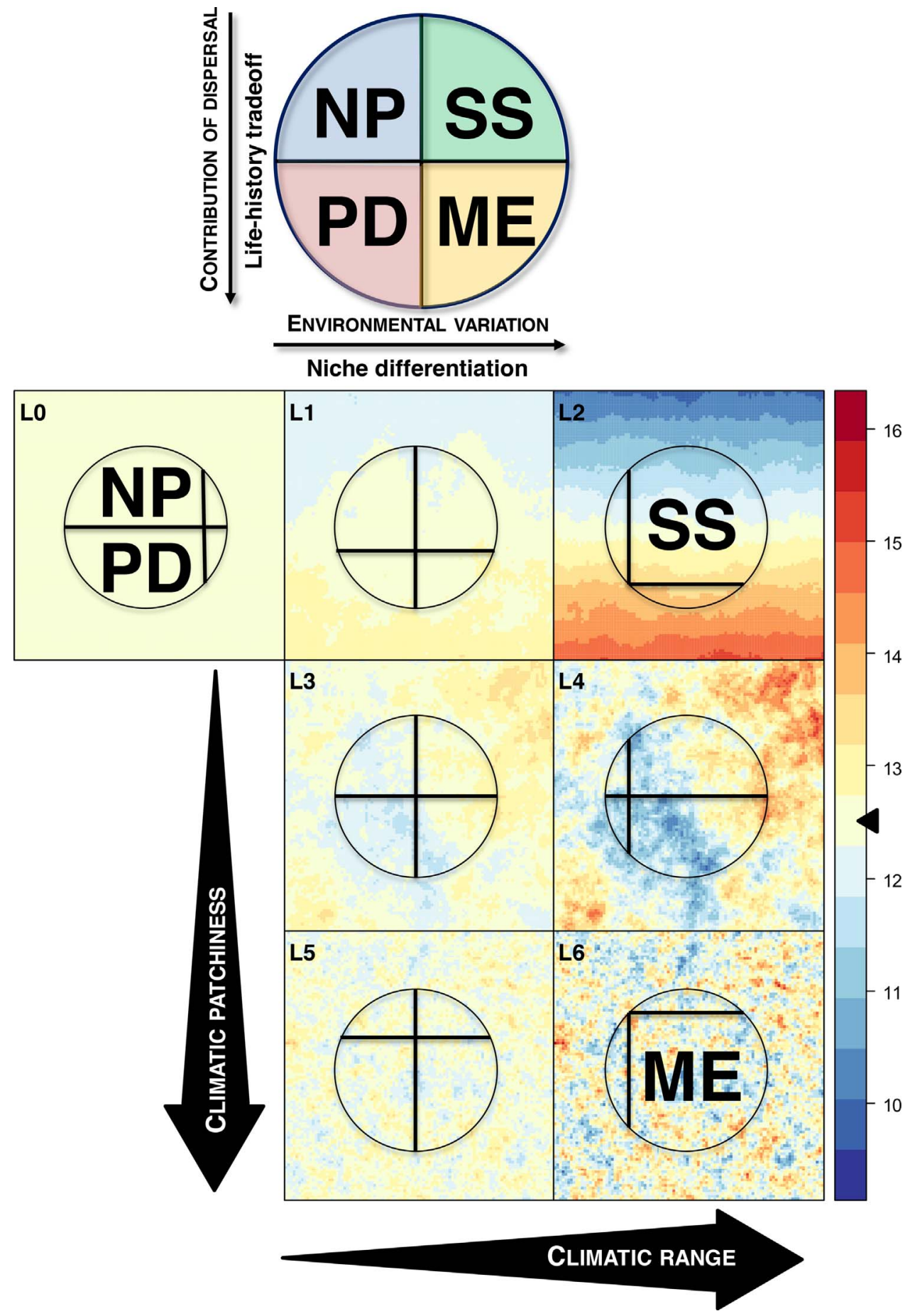

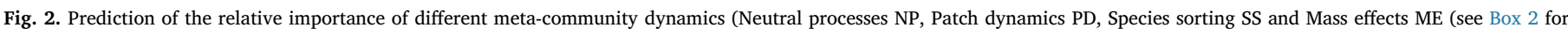
explanation)) (upper panel) in response to the climatic heterogeneity in the landscape (lower panels). The seven landscapes are the same as in Fig. 1.

have a suitable microclimate patch nearby. At the same time, these populations are likely to have been under selection for better dispersal capacity and wider niches because they have been exposed to such. The populations remaining in these landscapes should thus be better equipped to stay within the landscape. In L1-L6, in contrast to L0, for which species have to migrate outside the landscape if they cannot adapt locally, species can move across the landscape to track the climatic change. Species may go extinct within the landscape if (i) dispersal distances to track the species' niche exceed the species' dispersal capacity, (ii) the available habitat area within the landscape becomes too small to support a viable (meta-) population or (iii) the species' climatic niche is no longer available within the landscape (e.g., very cold-adapted species represented by the blue curve). In L1 the risk of colonisation time-lags and extinctions is expected to be higher than in L2 but this will depend heavily on species climatic tolerance, dispersal capacity and life-history traits (Alsos et al., 2012, 2015; Bertrand et al., 2011; Lenoir et al., 2008).

The average dispersal distance required to track a given climate change within the landscape window decreases from L1 via L3 to L5, requiring successively smaller dispersal capacity for survival. L4 and L6 will offer even better opportunities to disperse between patches under dramatic climate changes, even for dispersal-limited species. There is a high probability of encountering a patch nearby with suitable microclimate unless the microclimatic niche has vanished for that species (i.e. the species represented by blue and purple curves in Fig. 1 may loose their niches 
after warming), resulting in low dispersal limitation-related extinction rates and short time-lags. New neighbours will colonise at a faster rate. We expect that such rapid changes will pose challenges for species with slow life histories (cf. long-lived species with limited colonisation capacity) (Lenoir and Svenning, 2013; Tscharntke et al., 2012; Vranckx et al., 2012), and they will rely more on their ability to tolerate climate changes (De Witte and Stöcklin, 2010). The more fragmented landscapes, however, will also encompass smaller and more fragmented populations that may be more vulnerable to climatic fluctuations.

Our example landscapes illustrate how the adaptations resulting from the selective pressures that have been shaping the populations inhabiting homogeneous versus heterogeneous landscapes may be the opposite of the adaptations populations will need to survive in those landscapes under a rapid climate change. Populations in homogeneous landscapes have been under selection for traits allowing them to persist under rather homogeneous conditions, but may, in the face of climate change, be required to migrate over large distances (outside the landscape) if they cannot tolerate or adapt to the new conditions. In contrast, populations inhabiting heterogeneous landscapes have better opportunities to "stay" within their landscape throughout short-distance displacements and yet are also better adapted to disperse over longer distances and establish in a wider range of conditions due to historical selection pressures towards better dispersal and wider niches.

\section{Communities in landscapes of varying climatic heterogeneity}

Landscape structure and the associated differences in climatic range and patchiness will have consequences for community-level processes in the landscape (Tscharntke et al., 2012). The meta-community paradigm (Box 2), as described by Chesson (2000) and Leibold et al. (2004), is a useful starting point for exploring these implications. Here we assume that meta-community dynamics are driven to various degrees by neutral processes, patch dynamics, species sorting, and mass effects (Leibold et al., 2004). Climatically homogeneous landscapes, as exemplified by L0, are not likely to support communities in which climate niche-based processes, such as species sorting or mass effects, play important roles in maintaining species diversity (Fig. 2). There is no climate-driven habitat variation, and the populations that inhabit these landscapes share the same climate niche (see above). The total suitable habitat area is large and climatically homogeneous, which will increase the probability of community assembly based on either neutral processes, where the co-existence results from the very slow stochastic extinction rates of demographically equivalent species within a relatively large population area, or patch dynamics, with species co-existence permitted by a trade-off between dispersal and competitive abilities (Fig. 2).

In contrast, landscapes encompassing a wider range of climatic conditions (L1-L6) have more climate niche space available and there is scope for coexistence based on climate niche partitioning and hence for species sorting and/or mass effects to operate (Fig. 2). The climatic range is equal for all landscapes at the same position along the climate range gradient (for L1, L3, and L5 or for L2, L4, and L6), and the total area of suitable microclimate for any particular species is therefore also equal for the landscapes within each of these columns. It follows that climatic niche-partitioning processes (i.e., species sorting and/or mass effects) is likely to be intermediately important across L1, L3, and L5, and of overriding importance across L2, L4 and L6. As we move from L0 via L1 to L2, the average habitat area available for each species decreases, but for each species the available area is not fragmented (high auto-correlation), leading to an overall decrease in the relative contribution of dispersal to community dynamics.

Towards the lower parts of Fig. 2, both the average patch size of suitable habitats and the dispersal distance between patches decreases, leading to increased probabilities of both local extinction and re-colonisation of locallyextinct populations. The climate gradient length is equal within each column (e.g., L2, L4 and L6) and the importance of climatic niche-partitioning processes (the combined effect of species sorting and mass effects) is hence constant. However, with increased fragmentation, the probability that a dispersed propagule ends up in a 'sink' population increases, and the relative importance of mass effects is therefore expected to increase at the cost of efficient species sorting (Fig. 2). In L6, however, the decrease in dispersal distances between patches might be so important that, for some species, the landscape is perceived as more homogeneous than L3 and L4. Hence, neutral dynamics could be expected to operate, but within several "parallel communities" each consisting of few species with very specific climatic tolerances. Mass effects are then occurring between these parallel communities, causing all the species to seemingly coexist in the same landscape.

\section{Consequences of microclimatic heterogeneity for communities under climate change}

In large homogeneous landscapes where diversity is maintained by neutral and patch-dynamics processes, such as L0, there is little climate niche variation among species. Under climate change, persistence due to shifts in species' realised niche is possible as long as the climate change is within the fundamental niche limits of the species (Lenoir and Svenning, 2015). As the current climate no longer overlaps with the fundamental climatic niches of many of the species in the community, extinction rates are likely to increase sharply, and the ensuing gaps will mostly receive non-suitable recruits. This will result in unsaturated communities, probably with decreased levels of interspecific competitive interactions, which could lead to shifts or expansion of realised niches (cf. Lenoir et al., 2010) and increased probability of persistence for the remaining species. Longterm maintenance of biodiversity and ecological functions in such landscapes will require local extinctions and immigration, and hence remnant population dynamics (Eriksson, 1996, 2000), storage effects (Chesson and Warner, 1981) and dispersal limitation on long-distance dispersal from outside the landscape will result in severe time-lags. Such communities may exhibit considerable unpaid extinction debts (Jackson and Sax, 2010; Kuussaari et al., 2009), as species sorting processes will be inefficient in increasingly unsaturated communities consisting of species poorly adapted to the new climatic conditions. On the other hand, when individuals dispersing in from outside the landscape do eventually arrive, these unsaturated communities are likely to be readily invasible (colonisable) and new species with good dispersal and establishment capacities are likely to be favoured. We therefore expect communities in homogeneous landscapes to experience relatively slow species loss, and low levels of landscape-scale reshuffling over time (cf. time lag and climatic debt, sensu Bertrand et al., 2016). In the long term and with dramatic climate change exceeding the tipping point, we expect greater proportional species loss (climatic debt being paid off) here than in heterogeneous landscapes.

In heterogeneous landscapes (L1-L6), climate change is likely to result in species displacement along the climatic gradient, with direction and rate of the realized community change shaped by the interplay between local dispersal and species-sorting processes operating within the landscape (i.e., paralleling the processes operating in the landscape under a stable climate; Fig. 2). In general terms, landscapes with broader climatic ranges will have smaller available habitat area for any given climatic regime and hence higher extinction probability under climate change compared to more homogeneous landscapes. However, the finer-grained spatial heterogeneity of patchy landscapes implies, on average, that a broader range of climatic conditions are available within a given distance from any particular point in the landscape, and hence an influx to patches of species with a broad range of climaticniche requirements. As discussed above, a species pool adapted to survival in a fragmented landscape may also be better equipped for dispersal within the landscape. The net effect is less dispersal limitation, shorter establishment time-lags, and faster equilibration of the communities to new climatic conditions in patchy compared to homogeneous landscapes. Only the warmest patches may experience problems getting new species from within the landscape. However, at the same time, good dispersal abilities coupled with greater proximity between different habitat types will also result in greater impacts of mass effects on communities within these heterogeneous landscapes (Fig. 2). These mass effects will tend to delay the realized community change in 
response to climate change in patchy landscapes. Indeed, as long as a sufficient number of source populations are still available within the landscape, communities may appear resistant to climate change (Fig. 2). These contrasting effects of niche availability and patchiness on metacommunity processes within the landscapes thus predicts better climatic-niche tracking across intermediate landscapes (L1 to L5), with shorter time-lags here than in less (L0) or more (L6) fragmented landscapes where greater tolerances to climate change and greater mass effects, respectively, delay community turnover in species composition.

The shift in relative importance of underlying meta-community processes (from neutral processes and patch dynamics via species sorting to mass effects; Fig. 2) as well as the differences in selective pressures (increasing dispersal ability, Fig. 1) may be instrumental in driving differences in community-level response along the gradient from homogeneous to heterogeneous landscapes. At the same time, these same processes (notably, the mass effects) will tend to delay the change in underlying community dynamics in heterogeneous landscapes, resulting in an apparent resistance to climate change.

\section{The impact of temporal variation, and non-climatic confounding factors}

In addition to the general framework discussed above, other aspects of scale, temporal climatic variation, other niche requirements, biotic interactions, and disturbance will affect populations and communities under climate change. First, climatic heterogeneity varies in time as well as in space, and this also shapes the characteristics of populations and communities, and we may, for example, expect populations and communities with a history of exposure to strong temporal climatic variation due to seasonality or recurring extreme events to cope better with climate changes compared to landscapes in regions with less variable weather and climate. Second, biotic interactions can modify both microclimate and the ability of species to track their climate (Leathwick and Austin, 2001; Wisz et al., 2013). For instance, species colonisation rates may be enhanced by facilitation (Anthelme et al., 2014) or by zoochory (Cunze et al., 2013), and they may be delayed by interference (Pellissier et al., 2010). The strength of biotic interactions are however themselves often dependent on climate (Pellissier et al., 2013; Anthelme et al., 2014; Alexander et al., 2015; Olsen et al., 2016), and may therefore also enforce processes determined by landscape heterogeneity.

The rate and magnitude of climate change will partly determine the need for adaptation or required dispersal capacity for climate tracking (Sandel et al., 2011), and the disturbance frequency in a landscape, whether topographically homogeneous or heterogeneous, also imposes selective pressures on the species. Disturbance creates additional temporal and spatial heterogeneity in plant populations and communities, imposes distinct selective pressures (Tscharntke et al., 2012), and interacts with community dynamics (Levins and Culver, 1971; Tilman, 1994). Communities dominated by disturbance-adapted species will hence change faster than communities dominated by more stress-tolerant or competitive species (sensu Grime, 2001). This is not only because the species in the landscape are adapted to rapid changes, but also because the landscape itself will likely be subjected to disturbance in the future providing gaps in the vegetation for new colonisations (Vandvik and Goldberg, 2005, 2006). Many areas with high disturbance are associated with intense use by human or other animals and are often found in flat areas. Therefore, disturbance may cause topographically homogeneous landscapes to change faster than expected from the microclimatic variation patterns outlined above.

\section{Conclusion}

A growing number of studies points to the importance of landscape topography in modifying the rate of change in populations and communities (Tscharntke et al., 2012). For instance, findings from Bertrand et al. (2011) suggest that the extinction debt in forest plant communities is much more important in the lowlands than in the highlands in France. Spasojevic et al. (2013) and De Frenne et al. (2013) however, showed that alpine and forest plant communities are dynamic through time when studied at a fine spatial scale, even for the species distributions that on a broad scale seem to show extinction debts (Bertrand et al., 2011). We argue that landscapes with high microclimatic heterogeneity will contain populations and communities that have better opportunities for coping with climate change than those of climatically more homogeneous landscapes. However, at the same time, the characteristics of populations in heterogeneous landscapes may also compromise the monitoring of species-environment relationships, due to mass effects. In contrast, populations and communities of climatically more homogeneous landscapes may be relatively more vulnerable to climate change as they can only persist in the long run if they adapt to the new environment, if their realised niches are relaxed, or if they persist through extreme longevity and remnant populations. Nevertheless, lower immigration rates and less-saturated communities may provide opportunities for niche expansion and rapid evolution in homogeneous landscapes under a changing climate. Species and communities in homogeneous landscapes may therefore be more resistant to climate change than predicted solely from the current realised niches of the species and the current community dynamics.

To improve our understanding of population and community responses to climatic change, future studies need to consider the microclimatic heterogeneity of the landscapes in which the species are found and the selective pressures that may have shaped the populations and communities in these landscapes. We here introduced a very simplified theorethical framework to illustrate how the spatial patterns in microclimatic range and patchiness, closely associated to the various effects of topography and variables outlined in Box 1, may affect alpine community dynamics in response to climate change. Synthesis and tests of the importance of temporal climatic variation for the capacity for persistence or migration of populations and communities are also needed. Considering the microclimatic heterogeneity driven by topographic complexity in Arctic and alpine ecosystems may help us better understand the resistance and resilience of populations and communities to changing climate.

\section{Acknowledgments}

This paper is the outcome of discussions during network meetings of the Stay or Go network funded by Nordforsk from 2011-2013 (Project number 29662 to BJG). JCS was supported by the European Research Council (ERC2012-StG-310886-HISTFUNC) and also considers this work a contribution to his VILLUM Investigator project (VILLUM FONDEN, grant 16549).

\section{References}

Ackerly, D.D., 2003. Community assembly, niche conservatism, and adaptive evolution in changing environments. Int. J. Plant Sci. 164, S165-S184.

Alexander, J.M., Diez, J.M., Levine, J.M., 2015. Novel competitors shape species' responses to climate change. Nature 525, 515-518.

Alpert, P., Simms, E.L., 2002. The relative advantages of plasticity and fixity in different environments: when is it good for a plant to adjust? Evol. Ecol. 16, 285-297.

Alsos, I.G., Ehrich, D., Thuiller, W., Eidesen, P.B., Tribsch, A., Schonswetter, P., Lagaye, C., Taberlet, P., Brochmann, C., 2012. Genetic consequences of climate change for northern plants. Proc. Royal Soc. B: Biol. Sci. 279, 2042-2051.

Alsos, I.G., Ehrich, D., Eidesen, P.B., Solstad, H., Westergaard, K.B., Schonswetter, P., Tribsch, A., Birkeland, S., Elven, R., Brochmann, C., 2015. Long-distance plant dispersal to North Atlantic islands: colonization routes and founder effect. AoB Plants 7.

Anthelme, F., Cavieres, L.A., Dangles, O., 2014. Facilitation among plants in alpine environments in the face of climate change. Front. Plant Sci. 5. http://dx.doi.org/10. 3389/fpls.2014.00387.

Armbruster, W.S., Rae, D., Edwards, M.E., 2007. Topographic complexity and biotic response to high-latitude climate change: variance is as important as the mean. In: Ørbæk, J.B., Kallenborn, R., Tombre, I., Hegseth, E.N., Falk-Petersen, S., Hoel, A.H. (Eds.), Arctic-Alpine Ecosystems and People in a Changing Environment. Springer Verlag, pp. 105-122.

Bertrand, R., Lenoir, J., Piedallu, C., Riofrio-Dillon, G., de Ruffray, P., Vidal, C., Pierrat, J.C., Gegout, J.C., 2011. Changes in plant community composition lag behind climate warming in lowland forests. Nature 479, 517-520.

Bertrand, R., Riofrío-Dillon, G., Lenoir, J., Drapier, J., de Ruffray, P., Gégout, J.C., Loreau, M., 2016. Ecological constraints increase the climatic debt in forests. Nat. Comm. http://dx.doi.org/10.1038/ncomms12643.

Birks, H.J.B., Willis, K.J., 2008. Alpines, trees, and refugia in Europe. Plant Ecol. Divers. $1,147-160$. 
Botero, C.A., Weissing, F.J., Wright, J., Rubenstein, D.R., 2015. Evolutionary tipping points in the capacity to adapt to environmental change. Proc. Natl. Acad. Sci. U. S. A. 112, 184-189.

Brown, J.H., Kodric-Brown, A., 1977. Turnover rates in insular biogeography - effect of immigration on extinction. Ecology 58, 445-449.

Chase, J.M., Leibold, M.A., 2003. Ecological Niches. University of Chicago Press, Chicago, IL.

Cheddadi, R., Birks, H.J.B., Tarroso, P., Liepelt, S., Gomory, D., Dullinger, S., Meier, E.S., Hulber, K., Maiorano, L., Laborde, H., 2014. Revisiting tree-migration rates: Abies alba (Mill.) a case study. Veg. Hist. Archaeobot. 23, 113-122.

Chesson, P.L., Warner, R.R., 1981. Environmental variability promotes coexistence in lottery competitive-systems. Am. Nat. 117, 923-943.

Chesson, P., 2000. Mechanisms of maintenance of species diversity. Annu. Rev. Ecol. Syst. $31,343-366$.

Chevin, L.M., Lande, R., Mace, G.M., 2010. Adaptation, plasticity, and extinction in a changing environment: towards a predictive theory. PLoS Biol. 8.

Clark, J.S., Fastie, C., Hurtt, G., Jackson, S.T., Johnson, C., King, G.A., Lewis, M., Lynch, J., Pacala, S., Prentice, C., Schupp, E.W., Webb, T., Wyckoff, P., 1998. Reid's paradox of rapid plant migration - dispersal theory and interpretation of paleoecological records. Bioscience 48, 13-24.

Cunze, A., Heidel, F., Tackenberg, O., 2013. Are plant species able to keep pace with the rapidly changing climate? PLoS One 8. http://dx.doi.org/10.1371/journal.pone. 0067909.

De Frenne, P., Rodriguez-Sanchez, F., Coomes, D.A., Baeten, L., Verstraeten, G., Vellend, M., Bernhardt-Romermann, M., Brown, C.D., Brunet, J., Cornelis, J., Decocq, G.M., Dierschke, H., Eriksson, O., Gilliam, F.S., Hedl, R., Heinken, T., Hermy, M., Hommel, P., Jenkins, M.A., Kelly, D.L., Kirby, K.J., Mitchell, F.J.G., Naaf, T., Newman, M., Peterken, G., Petrik, P., Schultz, J., Sonnier, G., Van Calster, H., Waller, D.M., Walther, G.R., White, P.S., Woods, K.D., Wulf, M., Graae, B.J., Verheyen, K., 2013. Microclimate moderates plant responses to macroclimate warming. Proc. Natl. Acad. Sci. U. S. A. 110, 18561-18565.

De Witte, L.C., Stöcklin, J., 2010. Longevity of clonal plants: why it matters and how to measure it. Ann. Bot. Lond. 106, 859-870.

Dickinson, M.G., Orme, C.D.L., Suttle, K.B., Mace, G.M., 2014. Separating sensitivity from exposure in assessing extinction risk from climate change. Sci. Rep. 4.

Dobrowski, S.Z., Abatzoglou, J., Swanson, A.K., Greenberg, J.A., Mynsberge, A.R., Holden, Z.A., Schwartz, M.K., 2013. The climate velocity of the contiguous United States during the 20th century. Glob. Change Biol. 19, 241-251.

Eriksson, O., 1996. Regional dynamics of plants: a review of evidence for remnant, source-sink and metapopulations. Oikos 77, 248-258.

Eriksson, O., 2000. Functional roles of remnant plant populations in communities and ecosystems. Glob. Ecol. Biogeogr. 9, 443-449.

Feurdean, A., Bhagwat, S.A., Willis, K.J., Birks, H.J.B., Lischke, H., Hickler, T., 2013. Tree migration-rates: narrowing the gap between inferred post-glacial rates and projected rates. PLoS One 8.

Franklin, J., Davis, F.W., Ikegami, M., Syphard, A.D., Flint, L.E., Flint, A.L., Hannah, L., 2013. Modeling plant species distributions under future climates: how fine scale do climate projections need to be? Glob. Change Biol. 19, 473-483.

Graae, B.J., Ejrnaes, R., Lang, S.I., Meineri, E., Ibarra, P.T., Bruun, H.H., 2011. Strong microsite control of seedling recruitment in tundra. Oecologia 166, 565-576.

Graae, B.J., De Frenne, P., Kolb, A., Brunet, J., Chabrerie, O., Verheyen, K., Pepin, N., Heinken, T., Zobel, M., Shevtsova, A., Nijs, I., Milbau, A., 2012. On the use of weather data in ecological studies along altitudinal and latitudinal gradients. Oikos 121, 3-19.

Grime, J.P., 2001. Plant Strategies, Vegetation Processes, and Ecosystem Properties. John Wiley \& Sons, Chichester.

Grimmond, C.S.B., Robeson, S.M., Schoof, J.T., 2000. Spatial variability of micro-climatic conditions within a mid-latitude deciduous forest. Clim. Res. 15, 137-149.

Hampe, A., Jump, A.S., 2011. Climate relicts: past, present, future. Annu. Rev. Ecol. Evol. Syst. 42, 313-333.

Hanski, I., 1998. Metapopulation dynamics. Nature 396, 41-49.

Holt, R.D., 1993. Ecology at the mesoscale: the influence of regional processes on loca communities. In: Ricklefs, R.E., Schluter, D. (Eds.), Species Diversity Ecological Communities. University of Chicago Press, Chicago, Illinois, pp. 77-88.

Hubbell, S.P., 2001. The Unified Neutral Theory of Biodiversity and Biogeography. Princeton University Press, Princeton.

Jackson, S.T., Sax, D.F., 2010. Balancing biodiversity in a changing environment: extinction debt, immigration credit and species turnover. Trends Ecol. Evol. 25, 153-160.

Jump, A.S., Peñuelas, J., 2005. Running to stand still: adaptation and the response of plants to rapid climate change. Ecol. Lett. 8, 1010-1020.

Körner, C., Basler, D., Hoch, G., Kollas, C., Lenz, A., Randin, C.F., Vitasse, Y., Zimmermann, N.E., 2016. Where, why and how? Explaining the low-temperature range limits of temperate tree species. J. Ecol. 104, 1076-1088.

Körner, C., 2003. Alpine Plant Life Functional Plant Ecology of High Mountain Ecosystems. Springer-Verlag, Heidelberg.

Körner, C., 2004. Mountain biodiversity, its causes and function. Ambio Spec. Rep. 13, $11-17$.

Kerr, J.T., Packer, L., 1997. Habitat heterogeneity as a determinant of mammal species richness in high-energy regions. Nature 385, 252-254.

Kuussaari, M., Bommarco, R., Heikkinen, R.K., Helm, A., Krauss, J., Lindborg, R., Öckinger, E., Pärtel, M., Pino, J., Rodà, F., Stefanescu, C., Teder, T., Zobel, M., Steffan-Dewenter, I., 2009. Extinction debt: a challenge for biodiversity conservation. Trends Ecol. Evol. 24, 564-571.

Lande, R., 1993. Risks of population extinction from demographic and environmental stochasticity and random catastrophes. Am. Nat. 142, 911-927.

Leathwick, J.R., Austin, M.P., 2001. Competitive interactions between tree species in New Zealand's old-growth indigenous forests. Ecology 82, 2560-2573.

Leibold, M.A., Holyoak, M., Mouquet, N., Amarasekare, P., Chase, J.M., Hoopes, M.F., Holt, R.D., Shurin, J.B., Law, R., Tilman, D., Loreau, M., Gonzalez, A., 2004. The metacommunity concept: a framework for multi-scale community ecology. Ecol. Lett.
7, 601-613.

Leibold, M.A., Economo, E.P., Peres-Neto, P., 2010. Metacommunity phylogenetics: separating the roles of environmental filters and historical biogeography. Ecol. Lett. 13, 1290-1299.

Lenoir, J., Svenning, J.C., 2013. Latitudinal and elevational range shifts under contemporary climate change. In: Levin, S.A. (Ed.), Encyclopedia of Biodiversity. Academic Press, 599-611.

Lenoir, J., Svenning, J.C., 2015. Climate-related range shifts - a global multidimensional synthesis and new research directions. Ecography 38, 15-28.

Lenoir, J., Gégout, J.C., Marquet, P.A., De Ruffray, P., Brisse, H., 2008. A significant upward shift in plant species optimum elevation during the 20th century. Science 320, 1768-1771.

Lenoir, J., Gégout, J.C., Guisan, A., Vittoz, P., Wohlgemuth, T., Zimmermann, N.E. Dullinger, S., Pauli, H., Willner, W., Svenning, J.C., 2010. Going against the flow: potential mechanisms for unexpected downslope range shifts in a warming climate. Ecography 33, 295-303.

Lenoir, J., Graae, B.J., Aarrestad, P.A., Alsos, I.G., Armbruster, W.S., Austrheim, G., Bergendorff, C., Birks, H.J.B., Brathen, K.A., Brunet, J., Bruun, H.H., Dahlberg, C.J., Decocq, G., Diekmann, M., Dynesius, M., Ejrnaes, R., Grytnes, J.A., Hylander, K., Klanderud, K., Luoto, M., Milbau, A., Moora, M., Nygaard, B., Odland, A., Ravolainen, V.T., Reinhardt, S., Sandvik, S.M., Schei, F.H., Speed, J.D.M., Tveraabak, L.U., Vandvik, V., Velle, L.G., Virtanen, R., Zobel, M., Svenning, J.C., 2013. Local temperatures inferred from plant communities suggest strong spatial buffering of climate warming across Northern Europe. Glob. Change Biol. 19, 1470-1481.

Lenoir, J., Hattab, T., Pierre, G., 2017. Climatic microrefugia under anthropogenic climate change: implications for species redistribution. Ecography 40, 253-266.

Levins, R., Culver, D., 1971. Regional coexistence of species and competition between rare species. Proc. Natl. Acad. Sci. U. S. A. 68, 1246-1248.

Loarie, S.R., Duffy, P.B., Hamilton, H., Asner, G.P., Field, C.B., Ackerly, D.D., 2009. The velocity of climate change. Nature 462, 1052-U1111.

Logue, J.B., Mouquet, N., Peter, H., Hillebrand, H., Metacommunity Working G, 2011 Empirical approaches to metacommunities: a review and comparison with theory. Trends Ecol. Evol. 26, 482-491.

MacArthur, R.H., Wilson, E.O., 1963. An equilibrium theory of insular zoogeography. Evolution 17, 373-387.

May, M.R., Provance, M.C., Sanders, A.C., Ellstrand, N.C., Ross-Ibarra, J., 2009. A pleistocene clone of palmer's oak persisting in southern california. PLoS One 4.

Migliore, J., Baumel, A., Juin, M., Fady, B., Roig, A., Duong, N., Medail, F., 2013. Surviving in mountain climate refugia: new insights from the genetic diversity and structure of the relict shrub myrtus nivellei (Myrtaceae) in the sahara desert. PLoS One 8.

Moeslund, J.E., Arge, L., Bøcher, P.K., Dalgaard, T., Ejrnæs, R., Odgaard, M.V., Svenning, J.C., 2013. Topographically controlled soil moisture drives plant diversity patterns within grasslands. Biodivers. Conserv. 22, 2151-2166.

Mouquet, N., Loreau, M., 2003. Community patterns in source-sink metacommunities. Am. Nat. 162, 544-557.

Murphy, C.A., Foster, B.L., 2014. Soil properties and spatial processes influence bacterial metacommunities within a grassland restoration experiment. Restor. Ecol. 22, $685-691$.

Myers, J.A., Harms, K.E., 2009. Seed arrival, ecological filters, and plant species richness: a meta-analysis. Ecol. Lett. 12, 1250-1260.

Nicotra, A.B., Atkin, O.K., Bonser, S.P., Davidson, A.M., Finnegan, E.J., Mathesius, U., Poot, P., Purugganan, M.D., Richards, C.L., Valladares, F., van Kleunen, M., 2010. Plant phenotypic plasticity in a changing climate. Trends Plant Sci. 15, 684-692.

Olsen, S.L., Töpper, J.P., Skarpaas, O., Vandvik, V., Klanderud, K., 2016. From facilitation to competition: temperature-driven shift in dominant plant interactions affects population dynamics in semi-natural grasslands. Glob. Change Biol. 22, 1915-1926.

Opedal, O.H., Armbruster, W.S., Graae, B.J., 2015. Linking small-scale topography with microclimate, plant species diversity and intra-specific trait variation in an alpine landscape. Plant Ecol. Divers. 8, 305-315.

Pearson, R.G., Dawson, T.P., 2003. Predicting the impacts of climate change on the distribution of species: are bioclimate envelope models useful? Glob. Ecol. Biogeogr. 12, 361-371.

Pellissier, L., Bråthen, K.A., Pottier, J., Randin, C.F., Vittoz, P., Dubuis, A., Yoccoz, N.G., Alm, T., Zimmermann, N.E., Guisan, A., 2010. Species distribution models reveal apparent competitive and facilitative effects of a dominant species on the distribution of tundra plants. Ecography 33, 1004-1014.

Pellissier, L., Bråthen, K.A., Vittoz, P., Yoccoz, N.G., Dubuis, A., Meier, E.S., Zimmermann, N.E., Randin, C.F., Thuiller, W., Garraud, L., Van Es, J., Guisan, A., 2013. Thermal niches are more conserved at cold than warm limits in arctic-alpine plant species. Glob. Ecol. Biogeogr. 22, 933-941.

Pillar, V.D., Duarte, L.D.S., 2010. A framework for metacommunity analysis of phylogenetic. Ecol. Lett. 13, 587-596.

Randin, C.F., Engler, R., Normand, S., Zappa, M., Zimmermann, N.E., Pearman, P.B., Vittoz, P., Thuiller, W., Guisan, A., 2009. Climate change and plant distribution: local models predict high-elevation persistence. Glob. Change Biol. 15, 1557-1569.

Raunkiaer, C., 1934. The Life Forms of Plants and Statistical Plant Geography: Being the Collected Papers of C. Raunkiaer. Clarendon Press, Oxford.

Reino, L., Beja, P., Araujo, M.B., Dray, S., Segurado, P., 2013. Does local habitat fragmentation affect large-scale distributions?: The case of a specialist grassland bird. Divers. Distrib. 19, 423-432.

Roth, T., Plattner, M., Amrhein, V., 2014. Plants, birds and butterflies: short-term responses of species communities to climate warming vary by taxon and with altitude. PLoS One 9, e82490.

Sandel, B., Arge, L., Dalsgaard, B., Davies, R.G., Gaston, K.J., Sutherland, W.J., Svenning, J.C., 2011. The influence of late quaternary climate-change velocity on species endemism. Science 334, 660-664.

Scherrer, D., Körner, C., 2010. Infra-red thermometry of alpine landscapes challenges climatic warming projections. Glob. Change Biol. 16, 2602-2613.

Scherrer, D., Körner, C., 2011. Topographically controlled thermal-habitat differentiation 
buffers alpine plant diversity against climate warming. J. Biogeogr. 38, 406-416.

Slavich, E., Warton, D.I., Ashcroft, M.B., Gollan, J.R., Ramp, D., 2014. Topoclimate versus macroclimate: how does climate mapping methodology affect species distribution models and climate change projections? Divers. Distrib. 20, 952-963.

Spasojevic, M.J., Bowman, W.D., Humphries, H.C., Seastedt, T.R., Suding, K.N., 2013. Changes in alpine vegetation over 21 years: are patterns across a heterogeneous landscape consistent with predictions? Ecosphere 4, 117.

Svenning, J.C., Sandel, B., 2013. Disequilibrium vegetation dynamics under future climate change. Am. J. Bot. 100, 1266-1286.

Sykes, M.T., Prentice, I.C., Cramer, W., 1996. A bioclimatic model for the potential distributions of north European tree species under present and future climates. J. Biogeogr. 23, 203-233.

Telford, R.J., Vandvik, V., Birks, H.J.B., 2006. Dispersal limitations matter for microbial morphospecies. Science 312, 1015.

Tilman, D., 1994. Competition and biodiversity in spatially structured habitats. Ecology 75, 2-16.

Trivedi, M.R., Berry, P.M., Morecroft, M.D., Dawson, T.P., 2008. Spatial scale affects bioclimate model projections of climate change impacts on mountain plants. Glob. Change Biol. 14, 1089-1103.

Tscharntke, T., Tylianakis, J.M., Rand, T.A., Didham, R.K., Fahrig, L., Peter, B., Bengtsson, J., Clough, Y., Crist, T.O., Dormann, C.F., Ewers, R.M., Fruend, J., Holt, R.D., Holzschuh, A., Klein, A.M., Kleijn, D., Kremen, C., Landis, D.A., Laurance, W. Lindenmayer, D., Scherber, C., Sodhi, N., Steffan-Dewenter, I., Thies, C., van der Putten, W.H., Westphal, C., 2012. Landscape moderation of biodiversity patterns and processes - eight hypotheses. Biol. Rev. 87, 661-685.

Urban, M.C., Leibold, M.A., Amarasekare, P., De Meester, L., Gomulkiewicz, R., Hochberg, M.E., Klausmeier, C.A., Loeuille, N., de Mazancourt, C., Norberg, J., Pantel, J.H., Strauss, S.Y., Vellend, M., Wade, M.J., 2008. The evolutionary ecology of metacommunities. Trends Ecol. Evol. 23, 311-317.

Valladares, F., Matesanz, S., Guilhaumon, F., Araújo, M.B., Balaguer, L., Benito-Garzón, M., Cornwell, W., Gianoli, E., van Kleunen, M., Nicotra, A.B., Zavala, M.A., 2014. The effects of phenotypic plasticity and local adaptation on forecasts of species range shifts under climate change. Ecol. Lett. 17, 1351-1364.

Vandvik, V., Goldberg, D.E., 2005. Distinguishing the roles of dispersal in diversity maintenance and in diversity limitation. Folia Geobot. 40, 45-52.

Vandvik, V., Goldberg, D.E., 2006. Sources of diversity in a grassland metacommunity: quantifying the contribution of dispersal to species richness. Am. Nat. 168, 157-167.
Vranckx, G., Jacquemyn, H., Muys, B., Honnay, O., 2012. Meta-analysis of susceptibility of woody plants to loss of genetic diversity through habitat fragmentation. Conserv. Biol. 26, 228-237.

Wasof, S., Lenoir, J., Gallet-Moron, E., Jamoneau, A., Brunet, J., Cousins, S.A.O., De Frenne, P., Diekmann, M., Hermy, M., Kolb, A., Liira, J., Verheyen, K., Wulf, M., Decocq, G., 2013. Ecological niche shifts of understorey plants along a latitudinal gradient of temperate forests in north-western Europe. Glob. Ecol. Biogeogr. 22, 1130-1140.

Wasof, S., Lenoir, J., Aarrestad, P.A., Alsos, I.G., Armbruster, W.S., Austrheim, G., Bakkestuen, V., Birks, H.J.B., Bråthen, K.A., Broennimann, O., Brunet, J., Bruun, H.H., Dahlberg, C.J., Diekmann, M., Dullinger, S., Dynesius, M., Ejrnæs, R., Gégout, J.-C., Graae, B.J., Grytnes, J.-A., Guisan, A., Hylander, K., Jónsdóttir, I.S., Kapfer, J., Klanderud, K., Luoto, M., Milbau, A., Moora, M., Nygaard, B., Odland, A., Pauli, H., Ravolainen, V., Reinhardt, S., Sandvik, S.M., Schei, F.H., Speed, J.D.M., Svenning, J.C., Thuiller, W., Tveraabak, L.U., Vandvik, V., Velle, L.G., Virtanen, R., Vittoz, P., Willner, W., Wohlgemuth, T., Zimmermann, N.E., Zobel, M., Decocq, G., 2015. Disjunct populations of European vascular plant species keep the same climatic niches. Glob. Ecol. Biogeogr. 24, 1401-1412.

Wesser, S.D., Armbruster, W.S., 1991. Species distribution controls across a forest-steppe transition: a causal model and experimental test. Ecol. Monogr. 61, 323-342.

Westergaard, K.B., Jørgensen, M.H., Gabrielsen, T.M., Alsos, I.G., Brochmann, C., 2010 The extreme Beringian/Atlantic disjunction in Saxifraga rivularis (Saxifragaceae) has formed at least twice. J. Biogeogr. 37, 1262-1276.

Westergaard, K.B., Alsos, I.G., Engelskjøn, T., Flatberg, K.I., Brochmann, C., 2011. TransAtlantic genetic uniformity in the rare snowbed sedge Carex rufina. Conserv. Genet. $12,1367-1371$.

Whittaker, R.H., 1962. Classification of natural communities. Bot. Rev. 28, 1-239.

Wipf, S., Rixen, C., 2010. A review of snow manipulation experiments in Arctic and alpine tundra ecosystems. Polar Res. 29, 95-109.

Wisz, M.S., Pottier, J., Kissling, W.D., Pellissier, L., Lenoir, J., Damgaard, C.F., Dormann, C.F., Forchhammer, M.C., Grytnes, J.-A., Guisan, A., Heikkinen, R.K., Høye, T.T., Kühn, I., Luoto, M., Maiorano, L., Nilsson, M.-C., Normand, S., Öckinger, E., Schmidt, N.M., Termansen, M., Timmermann, A., Wardle, D.A., Aastrup, P., Svenning, J.-C., 2013. The role of biotic interactions in shaping distributions and realised assemblages of species: implications for species distribution modelling. Biol. Rev. 88, 15-30.

Zobel, M., 1997. The relative role of species pools in determining plant species richness. An alternative explanation of species coexistence? Trends Ecol. Evol. 12, 266-269. 